\title{
O PROCESSO DE REVISÃo DIALOGADA ENTRE PROFESSOR E ALUNOS DE LÍNGUA INGLESA: APENAS AVALIANDO TEXTOS ESCRITOS?
}

\author{
Francisco José Quaresma de Figueiredo*
}

\section{Resumo}

Este artigo apresenta um estudo no qual investigo um tipo de correção de erros escritos conhecido como conferência. Meu objetivo foi melhor compreender esse tipo de correção dialógica, bem como investigar as percepções das alunas e da professora da turma sobre esse tipo de atividade de correção. Este estudo baseia-se nas teorias sobre correção de erros e na teoria sociocultural, que partem do pressuposto de que a aprendizagem é facilitada pela interação. Os resultados mostram que, por meio da interação advinda das atividades de conferência, os alunos têm a chance de esclarecer pontos vagos em seus textos, bem como perceber que eles próprios são capazes de corrigir alguns de seus erros. O professor também tem a chance de avaliar o que os alunos sabem e o que ainda precisam aprender.

PaLAVRAs-CHAVE: aprendizagem de línguas, conferências, correção, interação.

The dialogic revision process between teacher and students of English: only evaluating written texts?

\section{Abstract}

This paper presents a study in which I investigate the text correction strategy for written English known as conference. My aim was to better understand this kind of dialogical correction, as well as to investigate students' and teacher's perception of their participation in this kind of correction activity. This study is supported by theories about error correction and by sociocultural theory, which assume that learning is facilitated through interaction. The results show that, through the interaction that takes place in conference activities, the students have the chance to clarify some vague aspects of their texts, which are pointed out during the conference, as well as to perceive that they themselves are able to correct some of their mistakes. The teacher also has the chance to evaluate what the students know and what they still have to learn.

KEY wORDs: conferences, correction, interaction, language learning.

\section{INTRODUÇÃo}

A literatura, na área de Lingüística Aplicada, mostra-nos que vários estudos foram realizados sobre correção de erros, no que concerne

* Doutor em Lingüística Aplicada pela UFMG. Professor de Língua Inglesa da Faculdade de Letras da UFG. E-mail: fquaresma@terra.com.br 


\section{Revista Solta a Voz, v. 16, n. 1}

à aprendizagem de uma segunda língua (L2) ou de uma língua estrangeira (LE) (ver, por exemplo, Hendrickson, 1978; Edge, 1989; Cohen e Cavalcanti, 1990; Bartram e Walton, 1994; Dellagnelo e Tomitch, 1999; Figueiredo, 2001, 2003; Lee, 2003, entre outros), e vários questionamentos sobre esse assunto foram feitos, muitos dos quais ainda aguardam respostas (Ellis, 1994).

O que se observa, na maioria desses estudos, é que a correção nem sempre é eficiente, pois não envolve o aprendiz nesse processo. Leki (1991, p. 204), por exemplo, afirma que "marcar os erros nos textos dos alunos não os ajuda a melhorar sua escrita nem a eliminar seus erros", visto que, ao receber a correção do professor, os alunos não teriam a oportunidade de refletir sobre seus erros e sobre o processo da escrita. Hyland (1998) afirma, ainda, que a motivação dos alunos e a confiança em si, como escritores, podem ser drasticamente afetadas por comentários vagos, ou negativos, que recebem em seus textos escritos.

Dessa forma, resolvi investigar um tipo de correção de erros, conhecido por conferência, em que o professor, em vez de marcar nos textos os erros dos alunos, dialoga com eles sobre os textos que escreveram, pois, como observam Zamel (1985), Goldstein e Conrad (1990) e Figueiredo (2001), a interação, a colaboração e a negociação, durante o processo de correção, podem promover uma melhor revisão de textos escritos.

Neste artigo, portanto, serão analisadas as melhorias dos textos, advindas desse processo dialógico de correção, a interação entre a professora da turma e suas alunas - e, por meio dessa interação, como ela avalia tais textos -, bem como as percepções que as alunas e a professora tiveram sobre essa forma de correção.

\section{CONFERÊNCIAS}

A correção colaborativa pode ser dividida, grosso modo, em dois tipos: aquela em que a maior parte da interação ocorre por escrito e aquela em que o texto é construído a partir de discussão oral (Murray, 1992). Um exemplo do primeiro tipo seriam os comentários que revisores ou editores fazem nos textos a serem publicados. Um exemplo do segundo são as conferências. As conferências são um tipo de correção dialogada entre professores e alunos, como a que acontece entre um orientador e seus orientandos. Esse tipo de correção baseia-se na 
Revista Solta a Voz, v. 16, n. 151

noção vygotskiana de que a interação e a colaboração favorecem a aprendizagem.

Segundo Vygotsky (1998), a aprendizagem ocorre dentro e a partir de interações significativas, pelas quais os indivíduos co-constroem o seu conhecimento. Dessa forma, pode-se perceber a importância que as conferências, por serem um processo dialógico, podem ter no processo de aprendizagem de uma nova língua.

Uma vantagem das conferências é a interação entre o professor e os alunos (Keh, 1990; Brender, 1998). O professor, nesse caso, é um leitor "ao vivo" e, dessa forma, é capaz de pedir esclarecimentos sobre pontos vagos, ajudar os alunos a resolver problemas, a tomar decisões. Nessa perspectiva, o professor é visto como participante do processo da escrita e não apenas como alguém que irá avaliar o produto.

Os alunos, por sua vez, durante as conferências, têm a oportunidade de tornarem-se aprendizes mais ativos no processo de correção do que em situações em que simplesmente recebem a correção feita pelo professor (Murphy, 2000; Haneda, 2004). Os professores, por meio desse tipo de correção interativa, podem conhecer melhor seus alunos (Fuller, 1987), e estes se sentem motivados pela atenção pessoal que recebem (Grabe e Kaplan, 1996).

Como qualquer outra forma de correção, as conferências apresentam, também, algumas limitações. Alguns estudiosos, como por exemplo Goldstein e Conrad (1990) e Brender (1998), revelam que a participação dos alunos, nas conferências, varia de aluno para aluno, e que há uma tendência de o professor dominar o discurso durante a sua realização. Todavia, segundo Walker (1992), o domínio do professor não se torna um problema se o foco da interação forem as reais necessidades dos alunos.

Apesar de existirem estudos sobre o uso de atividades de conferência em salas de aula de $\mathrm{L} 2$ ou $\mathrm{LE}$, poucos são os que examinam o discurso que ocorre durante esse tipo de correção (Goldstein e Conrad, 1990). Poucos, também, são os estudos que levam em consideração o papel do aluno no processo de correção e suas percepções sobre esse processo (Murphy, 2000). Dessa forma, este estudo pretende contribuir para uma melhor compreensão das atividades de conferência, por analisar o seu efeito na revisão de textos, a interação que ocorre em tais atividades, bem como as percepções das alunas e da professora da turma sobre esse tipo de revisão dialógica. 
52 Revista Solta a Voz, v. 16, n. 1

\section{Estudo}

Os dados a serem analisados foram coletados em uma turma do $2^{\circ}$ ano do Curso de Letras/Inglês, de uma universidade em Goiânia, durante o $2^{\circ}$ semestre de 2002. Participaram do estudo sete alunas e a professora da turma. Durante esse semestre, foram desenvolvidas várias atividades de escrita em língua inglesa, e diferentes formas de correção foram utilizadas: autocorreção, correção com os pares e conferência.

Neste estudo, como foi afirmado anteriormente, o foco de análise será sobre as atividades de conferência.

A professora da turma solicitou às alunas que escrevessem um texto cujo final seria: "[...] and that was the best/worst holiday of my life". Após a escritura, cada aluna, em sala de aula, teve seu texto corrigido oralmente pela professora. Essa interação foi gravada em fita cassete. Cada sessão de conferência durou de 15 a 20 minutos, o que totalizou 126 minutos de gravação.

Enquanto a professora realizava a correção dialogada com uma aluna, as outras escreviam um texto a ser entregue na aula seguinte. Para preservar a identidade das alunas, solicitei-lhes que escolhessem para si um pseudônimo. Após a reescritura, as alunas e a professora da turma foram entrevistadas individualmente sobre a correção empregada. Vale ressaltar que, por se tratar de uma turma de alunas que se encontrava no nível pré-intermediário de língua inglesa, a professora optou por realizar a correção em português.

\section{ANÁLISE DAS CONFERÊNCIAS}

A análise das atividades de conferência será realizada em três partes. Primeiramente, serão analisados os erros corrigidos durante o processo. Em seguida, as interações entre a professora e as alunas. Por fim, as percepções da professora e das alunas acerca das atividades de conferência.

\section{ANÁlise dos ERros}

Ao cotejar a primeira versão dos textos das alunas com a segunda versão, revisada após as atividades de conferência, pude perce- 
ber que a professora não corrigiu todos os erros existentes nos textos das alunas. Alguns foram por ela ignorados, por se tratar de erros relativos a alguns aspectos gramaticais ainda não aprendidos pelas alunas. A professora, dessa forma, comentou, prioritariamente, os erros que poderiam ser corrigidos pelas próprias alunas, como podemos observar na seguinte tabela:

TABELA 1. Quantidade de erros - conferência.

\begin{tabular}{lcccc}
\hline Tipo de erros & Comentados & Corrigidos & $\begin{array}{c}\text { Não } \\
\text { corrigidos }\end{array}$ & Criados \\
Gramática & 29 & 24 & 5 & - \\
Ordem das palavras & 10 & 9 & 1 & - \\
Ortografia & 12 & 12 & - & - \\
Palavra & 22 & 22 & - & - \\
desnecessária & & & & - \\
Palavra errada & 35 & 32 & 3 & 4 \\
Palavra faltando & 29 & 27 & 2 & - \\
Tempo verbal & 22 & 20 & 2 & 4 \\
Total & 159 & 146 & 13 & \\
Freqüência & $100 \%$ & $92 \%$ & $8 \%$ & \\
\hline
\end{tabular}

A Tabela 1 mostra-nos que a maioria dos erros comentados pela professora foi corrigida pelas alunas. Ao contrastar as transcrições das interações com os textos revisados, pude perceber que os erros corrigidos foram aqueles discutidos tanto pela professora quanto pelas alunas, ou seja, quando a professora envolvia as alunas no processo de correção. Esse fato corrobora os resultados obtidos por Goldstein e Conrad (1990), em seu estudo sobre atividades de conferência, quando afirmam que uma maior negociação ${ }^{1}$ favorece a correção de erros.

Os erros não corrigidos pelas alunas durante a reescritura dos textos foram geralmente aqueles corrigidos diretamente pela professora durante as conferências, porque a forma correta era desconhecida pelas alunas. Como a correção foi feita oralmente, as alunas, ao reescreverem os textos, não se lembravam mais da forma correta e mantinham o erro. Desse modo, durante a correção dialogada, caso o professor forneça uma palavra ou uma estrutura ainda desconhecida pelos alunos, é importante que ele escreva, no texto do aluno, a sugestão, pois possivelmente o aluno não se lembrará dela ao reescrever seu texto. 
54 Revista Solta a Voz, v. 16, n. 1

A Tabela 1 mostra-nos, também, que quatro erros foram criados após a correção dialogada com a professora. Em relação a esses erros criados, pude observar que foram cometidos pelas próprias alunas durante o processo de reescritura dos textos, pois, à medida que estes eram reescritos, as autoras dos textos acrescentavam-lhes novas sentenças, o que causava o surgimento de novos erros.

Quando, na entrevista, ${ }^{2}$ perguntei à professora se ela priorizava mais a forma do que o conteúdo, durante a correção, ela respondeu-me:

Bom, eu, não estava muito claro, pra mim, assim, eh, se era só forma ou só conteúdo. Acho que estava muito misturado. Às vezes, eu aceitava coisas pelo próprio nível de desenvolvimento deles. Eu pensava assim: "não, futuramente eles vão aprender outra forma”, por exemplo, tempo verbal. Como a gente escreveu muito sobre histórias, narrativas, então, naquele momento, ele deveria estar usando o past perfect, e eu vi que ele não tinha usado. Então, eu simplesmente esqueci aquilo ali, ou deixei como tava, no passado simplesmente e aí foi pra frente. Então, eu considerei a habilidade que eles têm hoje e não corrigi coisas que eles virão a aprender no futuro. Então, eu acho que foi uma mistura dos dois.

Essa afirmação da professora revela que ela usou um meio seletivo de correção - como sugerem alguns autores, a exemplo de Bartram e Walton (1994) e Figueiredo (2002). Inferi, assim, que havia um propósito no modo como a professora realizou a correção. Conforme ela relatou, ela focalizava, durante as conferências, aspectos já vistos pelas alunas. Em outras palavras, o fato de ela não ter corrigido todos os erros demonstra uma seletividade e não uma inconsistência. Isto serve para conscientizar-nos de que nem sempre a correção realizada pelos professores é inconsistente.

Vale ressaltar que, por meio da indicação da professora, as alunas foram capazes de se autocorrigirem; ou seja, dos 146 erros corrigidos, 62 foram feitos por elas mesmas durante as atividades de conferência, como pode ser observado na Tabela 2: 
TABELA 2. Quantidade de erros corrigidos pelas próprias alunas durante as conferências.

A correção dos erros pelas próprias alunas ocorreu, principalmente, pela forma como a professora realizou a correção. $\mathrm{Na}$ maior parte das vezes, ela instigava as alunas a encontrar, por elas mesmas, a forma correta, o que, a meu ver, é extremamente produtivo. Este fato serve para reforçar a idéia de que os alunos podem se autocorrigir se

\section{Tipo de erros} lhes dermos oportunidades para fazê-lo como será abordado na pró-

\section{Gramática} xima seção.

\section{Corrigidos}

\section{Corrigidos pelas próprias alunas}

$\begin{array}{lcc}\text { Gramática } & 24 & 12 \\ \text { Ordem das palavras } & \text { ANÁLISE DAS INTERAĞẼES } & 4 \\ \text { Ortografia } & 12 & 8\end{array}$

Palavra desnecessária Por meio da2zonversação, a proßessora pôde obter esclareciPalavra errada mentos sobre algun̨̧̊rechos não compręndidos nos textos. Em geral, Palavra faltando como foi afirmado 2 anteriormente, ela 1ึão fornecia a forma correta Tempo verbal Total Freqüência para as alunas. Ao contrário, a professorad deu, às alunas, oportunidades para que tentassemp $140 \%$ contrar a forma 62 grreta por si próprias. Ela só dizia a forma correta quando percebia que as alunas não a saberiam, ou quando, após várias tentativas, elas não conseguiam encontrar a resposta correta.

Vejamos um exemplo em que a professora, por meio de alguns questionamentos, ajuda a aluna a revisar seu texto. Podemos perceber que a correção se configura como um processo colaborativo, em que a aluna e a professora tentam encontrar a melhor maneira de a mensagem ser expressa. Elas estão conversando sobre o seguinte trecho: 
I had a blue bike. It wasn't beautiful but I was very satis fied with my old bike. Sone fiends haven'tibike

Professora: O que que seria aqui?

Vanessa: Hum?

Professora: Primeiro, tá have, seria have?

Vanessa: Não, had.

Professora: Isso. Então, o problema é com o tempo, mas você tá colocando na negativa, não é?

Vanessa: Hum, hum.

Professora: E pra fazer a negativa, como é que a gente faz? No passado?

Vanessa: Não é hadn't não?

Professora: Não. Deixa eu ver aqui mais pra frente onde você... Não, não tem outro exemplo aqui. Por exemplo, você fala I liked riding a bike, né? Se você fosse colocar essa frase no presente seria I like.

Vanessa: Hum, hum.

Professora: E como seria eu não gosto?

Vanessa: I don't like.

Professora: Isso, I don't, né, mas como a gente tá falando de passado, não seria don't.

Vanessa: $\quad$ Seria didn't.

Professora: Isso.

Vanessa: Ah, entendi.

Professora: Tem um probleminha de gramática e de tempo também. Então, ficaria some friends...

Vanessa: Didn'thave.

Professora: A bike.

Vanessa: Abike.

Professora: A bike, né, "and they borrowed". Aqui você queria dizer que eles pegavam emprestado.

Vanessa: Hum, hum.

Professora: Tá, mas eles pegavam emprestado o quê?

Vanessa: A bicicleta. 
Professora: De quem? Quando você pede emprestado, você pede emprestado alguma coisa...

Vanessa: Eu tive dificuldade porque eu queria colocar assim, pega emprestado deles.

Professora: Dos amigos, né?

Vanessa: Dos amigos.

Professora: Então, acho que tá faltando aqui uma parte, né, dos amigos, como é que seria? Amigos você sabe.

Vanessa: Of the friends?

Professora: Não, from.

Vanessa: From their friends.

Professora: Então, ficaria and they borrowed it from ...

Vanessa: $\quad$ From their friends...

Por meio dessa interação, Vanessa reescreveu o trecho da seguinte forma:

\footnotetext{
I had a blue bike. It wasn't brantiful but I was

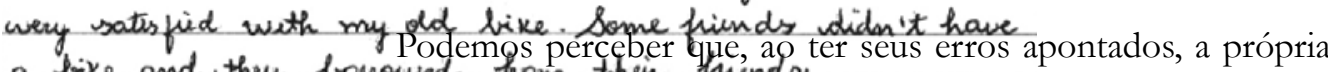
a bike and they bonowed trom thein thinds no caso, foi apenas a mediadora desse processo, o que pôde favorecer a autonomia da aluna.

Neste outro exemplo, a professora, por meio da interação, pôde pedir à aluna alguns esclarecimentos sobre pontos que estavam vagos em seu texto. O diálogo em foco é sobre a seguinte parte do texto de Thaís:

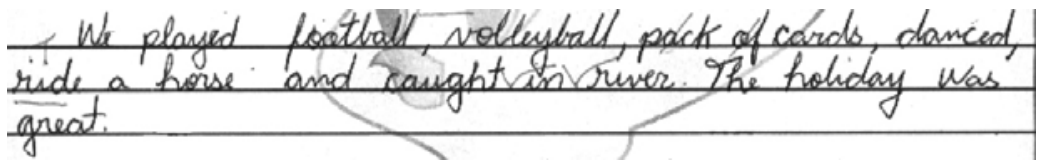

Professora: [...] "We played football, volleyball, pack of cards"?

Thaís: $\quad$ Seria baralho.

Professora: Então, seria só cards.

Thaís: $\quad$ É que eu olhei o correspondente no dicionário e aparece nessa forma.
} 
58 Revista Solta a Voz, v. 16, n. 1

Professora: É, mas we played cards. Você não jogou o baralho, a caixinha, literalmente, então a expressão é play cards. Então, aqui seria desnecessário. “...danced...”, e aqui nós temos um "ride a horse".

Thaís: $\quad$ Eu fiquei em dúvida.

Professora: Então ficou assim: we played football, danced e andar a cavalo.

Thaís: $\quad$ Eu não sabia qual palavra usar para..

Professora: Tá certo, ride a horse.

Thaís: Mas no caso tá faltando um conectivo?

Professora: Não. We played.

Thaís: $\quad$ Ah, no caso é o tempo.

Professora: Como seria?

Thaís: Rode?

Professora: Hum, hum... "and caught in river", que que você quis dizer?

Thaís: Pescamos no rio.

Professora: Ah, caught o quê?

Thaís: Fish?

Professora: Isso. Tá faltando, porque a gente pode pegar um monte de coisa lá. Caught fish, mas aqui no caso, a gente teria mais alguma coisa faltando.

Thaís: In the.

Professora: Isso. "The holiday was great." [...]

Nessa interação, podemos perceber que, muitas vezes, os alunos, ao escreverem seus textos em inglês, utilizam um dicionário bilíngüe que raramente apresenta um contexto adequado em que as palavras são usadas, o que explica o uso de pack of cards para se referir a baralho.

A interação entre a professora e a aluna fez com que esta última pudesse corrigir muitos dos seus erros e tornar o seu texto mais claro para um leitor, como podemos observar no trecho reescrito:

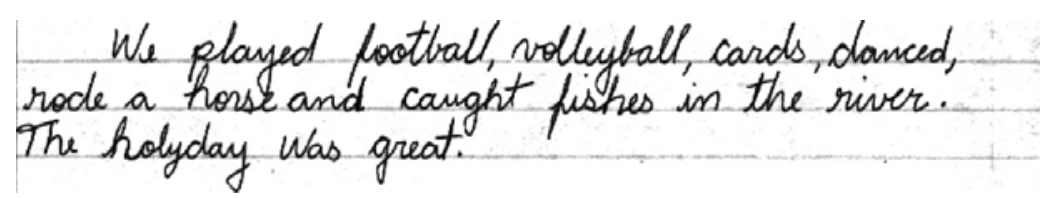


Conforme foi afirmado anteriormente, a professora fornecia, às alunas, a forma correta, em duas situações: quando as alunas não conseguiam, por si mesmas, corrigir seus textos, ou quando a forma correta era desconhecida por elas.

No exemplo a seguir, podemos perceber que a professora, por meio de várias perguntas, tenta fazer com que a aluna forneça-lhe a forma correta do passado do verbo break. Porém, ela não sabe o passado do referido verbo, e a professora, então, fornece-lhe a resposta.

Professora: Tem um probleminha aqui (referindo-se à palavra broked). A gente tem o verbo break, ele é regular ou irregular?

Suélen: $\quad$ Não sei professora.

Professora: Você colocou ed e colocou broked.

Suélen: $\quad$ Ah, porque pra mim ele é assim, né?

Professora: Hum, hum, sem o $d$. Por que você colocou o $d$ ?

Suélen: Porque é passado.

Professora: Mas, broke já não está no passado?

Suélen: $\quad$ Não sei.

Professora: Broke.

Suélen: $\quad$ Ah, não sei professora.

Professora: Que isso? Não tem have/had, is/was?

Suélen: $\quad$ Eu sei, mas...

Professora: Então, break

Suélen: $\quad$ Eu não sei direito os verbos não.

Professora: Então, antes você tinha colocado sem o $d$.

Suélen: $\quad$ Não, eu pus assim porque pra mim era broked.

Professora: Mas, se aqui já tá no passado, então não precisa, já está dizendo, porque ele é irregular.

Suélen: $\quad$ Eu não sabia que tava errado.

Professora: Então, break é um verbo irregular e ele não vai ter o $d$, né?

Suélen: $\quad$ No infinitivo é $a$ (referindo-se à grafia de break), o que é aqui?

Professora: É assim (escreve break).

Suélen: $\quad$ E assim sem o $d$ tá certo?

Professora: Tá. Broke. [...] 
60 Revista Solta a Voz, v. 16, n. 1

Já neste outro exemplo, a professora fornece, à outra aluna, a forma correta, por perceber que ela não conhece a palavra adequada ao contexto:

Professora: [...] "While this...”, isso aqui é português.

Anny: É.

Professora: Acho que essa palavra você não conhece, meanwhile. Você quer dizer, ao mesmo tempo, enquanto uma coisa acontecia, outra acontecia também, né, a palavra é meanwbile.

Durante a correção, a professora teve a oportunidade de mostrar às alunas que se interessou por seus textos, envolvendo-as no processo de revisão, como se pode observar no seguinte exemplo:

Professora: Por que você escolheu "My worst holiday"?

Anny: $\quad$ Ah, porque foi o que veio primeiro na minha cabeça, uma coisa, assim, mais marcante da minha vida, né, que no caso foi a pior. Algo, assim, como lembrança.

Professora: Vamos dar uma olhada nela. Onde que é São Francisco do Sul? Em qual estado que fica? Eu não entendi sua letra aqui, delerict.

Anny: Abandonada.

Professora: Vamos dar uma olhadinha, eu entendi toda a sua história e realmente foi uma tragédia (referindo-se ao que aconteceu com a aluna). Tem uns probleminhas que eu vou apontar pra você pra ver se a gente consegue resolver. [...]

O tom amigável utilizado pela professora serviu para deixar as alunas à vontade durante o processo de correção, como foi relatado por várias delas durante as entrevistas. Segundo Johnson (1992), a correção de textos de forma não-anônima - como a realizada durante as conferências e as correções com os pares - é uma atividade que ameaça a face dos interlocutores, fazendo, dessa forma, que utilizem estratégias de polidez para amenizar quaisquer tipos de críticas. 
Revista Solta a Voz, v. 16, n. 161

\section{Percepções das alunas e da Professora} SOBRE AS ATIVIDADES DE CONFERÊNCIA

As alunas puderam relatar pontos positivos e negativos em relação às atividades de conferência das quais participaram. Uma síntese de suas respostas pode ser visualizada no Quadro 1:

QUADRO 1. Percepções das alunas sobre as atividades de conferência.

\begin{tabular}{|c|c|}
\hline Pontos positivos & Pontos negativos \\
\hline $\begin{array}{l}\text { - Possibilidade de solução de dúvidas. } \\
\text { - Correção mais discreta do que a } \\
\text { realizada com a turma toda. } \\
\text { - O fato de a professora ter induzido } \\
\text { as alunas à forma correta fez com } \\
\text { que percebessem que elas próprias } \\
\text { podiam corrigir seus erros. }\end{array}$ & - Constrangimento ou vergonha. \\
\hline
\end{tabular}

De acordo com as alunas, elas foram capazes de se auto-corrigirem, quando seus erros lhes foram apontados, e tiveram a oportunidade de ter suas dúvidas resolvidas por meio da interação com a professora, como é ilustrado no seguinte exemplo:

Pesquisador: Eh... e a correção com a professora, como que foi a correção com a professora?

Vanessa: Ah, foi muito bom, porque eu fiz o meu texto, ela foi me mostrando né... a ordem, que, às vezes, eu não sabia colocar uma palavra... e ela falava, olha...por exemplo, teve uma ... no meu texto lá que eu deixei pela metade, porque eu não sabia complementar. Então, ela pegou, me explicou, me disse o porquê, e uma dúvida que surgiu também do then, do so, que eu não sabia usar os dois, né, ela me ajudou. E foi me falando, né, onde eu estava, assim, acertando. Os tempos verbais eu errava por falta de atenção mesmo, nossa... sempre era isso ... assim.

Apesar de terem se favorecido da correção dialogada com a professora, algumas alunas, como Sandy e Suélen, sentiram-se enver- 
gonhadas por terem seus erros apontados por ela, como pode ser verificado no seguinte relato de Sandy:

Sandy: $\quad[\ldots]$ com a professora acaba sendo a que ela te dá mais possibilidade, porque ela conhece mais, né? Então, ela te dá mais possibilidade. Às vezes, a colega não conhece tanto quanto a professora [...] mas só que, às vezes, você fica mais com vergonha com a professora... do que com a colega. Aí, você vai discutindo, com a colega você tem mais intimidade, alguma coisa assim... né? Então, você fica com mais liberdade. Com a professora, o único problema que tem é que você fica com receio.

A professora também considerou as atividades de conferência produtivas, pois ela pôde perceber o que suas alunas sabiam e o que precisava ainda ser trabalhado com elas. Uma síntese de suas percepções pode ser visualizada no seguinte quadro:

QUADRO 2. Percepção da professora sobre as atividades de conferência.

\begin{tabular}{|l|l|}
\hline \multicolumn{1}{|c|}{ Pontos positivos } & \multicolumn{2}{|c|}{ Pontos negativos } \\
\hline - É uma correção prazerosa, mais \\
$\begin{array}{l}\text { humanizadora. } \\
\text { - O professor percebe o que o aluno } \\
\text { sabe e o que ainda precisa aprender. } \\
\text { realizar a atividade de correção. }\end{array}$ \\
- Mostra aos alunos que eles são \\
capazes de se autocorrigirem. \\
- O professor pode mostrar ao aluno \\
que está satisfeito com o seu pro- \\
gresso e que se interessou pelo seu \\
texto.
\end{tabular}

Em virtude da interação face a face, possibilitada por essa forma dialógica de revisão de textos escritos, a professora considerou a correção humanística. Ela pôde, também, perceber o desenvolvimento de suas alunas no que tange ao processo da escrita. Todavia, ela relata que é uma atividade que demanda muito tempo, como pode ser observado no relato a seguir: 
Revista Solta a Voz, v. 16, n. 163

Pesquisador: E como que você avalia os pontos positivos e os negativos da conferência?

Professora: Eu acho que é uma atividade que tomaria tempo em sala de aula. Se bem que isso pode ser feito extra classe, não há nada que impeça, né? Mas como foi uma atividade que a gente utilizou ali em sala de aula, enquanto os outros alunos estão fazendo outra coisa, a gente pode estar fazendo isso lidando com esses problemas entre aspas, né? Eh, eu acho que, assim, vai ao encontro daqueles alunos que querem ainda ter a sua correção final. Então, isso é positivo pra eles. Mostra pra eles que eles sabem e mostra pra mim, enquanto professora, que eles sabem, né, uma vez apontados, porque isso ficou muito claro pra mim e queria que ficasse claro pra você também. Ele escreve e tal e faz uso do dicionário e tudo. Ele relê inclusive, muitas coisas passaram despercebidas e eles mesmos falaram que era por falta de revisão, eles mesmos lerem os próprios textos com esse objetivo em mente, né? Eh, então, eles, ao serem apontados que aquilo ali tava com algum probleminha, e que tipo de problema que era, eles puderam corrigir. Então, isso foi muito positivo também. Eh, e a interação one-to-one, né, é aquela coisa de você realmente se importar ali com o aluno, ver o progresso dele, elogiar o trabalho dele. Você deve ter notado que eu corrigi com alguns comentários. Então, eu gosto muito dessa parte mais humana que essa interação one-to-one dá para o aluno.

Como podemos perceber, por esse relato, a professora não avaliou apenas os textos escritos pelas alunas. Ela teve, também, a oportunidade de mostrar às alunas interesse pelos seus textos e de elogiar o trabalho feito por elas. Ela percebeu, ainda, que muitos dos erros foram corrigidos pelas próprias alunas, o que, segundo ela, é muito positivo. 


\section{Revista Solta a Voz, v. 16, n. 1}

\section{ConsideraÇõEs FinaIS}

Para aumentar a qualidade dos textos escritos pelos alunos, é preciso torná-los conscientes da importância da revisão e da reescritura dos textos por eles escritos. A revisão é um processo importante, pois novas idéias podem ser geradas e velhas idéias descartadas (Flower et al., 1986). É um processo pelo qual as idéias podem ser reorganizadas e reformuladas (Tsui, 1996). A revisão ajuda os alunos a refletir sobre a língua que estão aprendendo e a perceber a necessidade de tornar os seus textos mais claros para um leitor (Lucena, 1997).

Vimos que a interação decorrente das atividades de conferência fez com que as alunas participantes deste estudo tivessem a oportunidade de resolver suas possíveis dúvidas, com uma leitora "ao vivo" a professora - e de esclarecer aspectos vagos em seus textos, e, por meio dessa interação, puderam melhorá-los, tanto no que concerne à forma quanto ao conteúdo. Comentários escritos nos textos talvez não fossem tão esclarecedores nem para as alunas nem para a professora. Dessa forma, seria importante a realização de pesquisas que contrastassem os efeitos de comentários escritos e da correção dialogada, via conferência, na revisão de textos escritos por aprendizes de LE.

A professora, por sua vez, teve a oportunidade não só de avaliar os textos escritos pelas alunas, mas também de avaliar parte do conhecimento que as alunas tinham da língua-alvo e o que elas ainda precisam desenvolver. A professora teve, também, a chance de mostrar, às alunas, interesse por seus textos e de elogiar-lhes o trabalho feito. Por meio do diálogo, a professora pôde atender às reais necessidades de suas alunas, à medida que percebia as suas dificuldades no processo da escrita em uma LE. As alunas, quando se autocorrigiam, também tiveram a oportunidade de avaliar o conhecimento que tinham, até então, da língua que estavam aprendendo.

Um fato que merece uma certa reflexão é o tempo despendido na realização de atividades de conferência. Indubitavelmente, é uma atividade que demanda tempo, mas os resultados, como pudemos ver, são profícuos tanto para alunos quanto para professores. Devemos, portanto, considerar tais atividades como a programação da aula e não como algo que possa tomar o tempo da aula. Uma outra possibilidade, como foi sugerido pela própria professora, é a realização das atividades de conferência em um outro horário, que não a aula, agendado 
com os alunos. Cabe ao professor decidir qual é a melhor possibilidade, de acordo com o contexto em que ensina.

Em turmas de alunos de nível intermediário ou avançado, as atividades de conferência podem ser realizadas na língua-alvo. Desse modo, os alunos, além de terem seus textos revisados, terão mais uma forma de praticar oralmente a língua que estão aprendendo, por meio de interações significativas com o professor.

Uma das limitações deste estudo é o número reduzido de participantes, o que não possibilita algumas generalizações. No entanto, os resultados deste e de outros estudos (como, por exemplo, os realizados por Freedman e Sperling, 1985; Goldstein e Conrad, 1990; Villamil e Guerrero, 1996; Figueiredo, 2001) revelam a importância de utilizarem-se com mais freqüência, em sala de aula, atividades de correção dialogada, em que os alunos tenham um papel mais ativo no processo. Assim, estaremos dando-lhes oportunidades para que se tornem mais autônomos e mais reflexivos no que concerne ao processo de aprendizagem de línguas e, especialmente, ao processo da escrita.

\section{Notas}

1. Os tipos de erro aqui apresentados baseiam-se em um sistema de códigos que foi utilizado pela professora durante o processo de correção. Os erros de gramática, por exemplo, incluem o uso não adequado de artigos, flexões verbais, preposições etc. Os outros tipos de erros podem mais facilmente ser compreendidos pela própria nomenclatura utilizada.

2. $\mathrm{Na}$ análise conversacional, o termo "negociação" tem sido utilizado, geralmente, para referir-se às mudanças efetuadas pelos falantes no seu discurso, de modo a simplificá-lo e a se fazerem compreendidos, principalmente na interação entre falantes nativos e não-nativos (ver, por exemplo, Long, 1985; Swain, 2000). Neste estudo, o termo “negociação" será empregado para referir-se ao processo no qual leitores e escritores engajam-se para resolver possíveis problemas referentes aos seus textos, com o intuito de descobrir formas alternativas e novas possibilidades para torná-los mais claros para um leitor (Flower, 1994).

3. As entrevistas e as interações foram transcritas verbatim. 
66 Revista Solta a Voz, v. 16, n. 1

\section{REFERÊNCIAS}

BARTRAM, M.; WALTON, R. Correction: a positive approach to language mistakes. London: Language Teaching Publications, 1994.

BRENDER, A. Conferencing: an interactive way to teach writing. The Language Teacher Online, v. 22, n. 7, July 1998. Disponível em: < http://jaltpublications.org/tlt/files/98/jul/brender.html>. Acesso em: 5 mar. 2004.

COHEN, A. D.; CAVALCANTI, M. C. Feedback on compositions: teacher and student verbal reports. In: KROLL, B. (Ed.). Second language writing: research insights for the classroom. New York: Cambridge University Press, 1990. p. 155-176.

DELLAGNELO, A. C. K.; TOMITCH, L. M. B. Preferências de alunos-escritores em L2 com relação a estratégias de revisão de texto. Linguagem e Ensino, v. 2, n. 1, p. 73-86, 1999.

EDGE, J. Mistakes and correction. London: Longman, 1989.

ELLIS, R. The study of second language acquisition. Oxford: Oxford University Press, 1994.

FIGUEIREDO, F. J. Q. de. Correção com os pares: os efeitos do processo da correção dialogada na aprendizagem da escrita em língua inglesa. 2001. Tese (Doutorado em Letras) - Faculdade de Letras, Universidade Federal de Minas Gerais, Belo Horizonte, 2001.

- Aprendendo com os erros: uma perspectiva comunicativa de ensino de línguas. 2. ed. Goiânia: Ed. da UFG, 2002.

Formas diferentes de correção: o que cada uma delas pode dizer ao professor de línguas? Anais do V Seminário de Linguas Estrangeiras - UFG. Goiânia: Gráfica e Editora Vieira, 2003. p. 189-201.

FLOWER, L. The construction of negotiated meaning: a social cognitive theory of writing. Carbondale, IL: Southern Illinois University Press, 1994.

FLOWER, L. et al. Detection, diagnosis, and the strategies of revision. College Composition and Communication, v. 37, n. 1, p. 16-55, 1986.

FREEDMAN, S. W.; SPERLING, M. Written language acquisition: the role of response and the writing conference. In: FREEDMAN, S. 
W. (Ed.). The acquisition of written language: response and revision. New Jersey: Ablex, 1985. p. 106-130.

FULLER, D. C. Teacher commentary that communicates: practicing what we preach in the writing class. Journal of Teaching Writing, v. 6, n. 2, p. 307-317, 1987.

GOLDSTEIN, L. M.; CONRAD, S. M. Student input and negotiation of meaning in ESL writing conferences. Tesol Quarterly, v. 24, n. 3, p. 443-460, 1990.

GRABE, W.; KAPLAN, R. B. Theory \& practice of writing. New York: Longman, 1996.

HANEDA, M. The joint construction of meaning in writing conferences. Applied Linguistics, v. 25, n. 2, p. 178-219, 2004.

HENDRICKSON, J. M. Error correction in foreign language teaching: recent theory, research, and practice. The Modern Language Journal, v. 62, p. 387-398, 1978.

HYLAND, F. The impact of teacher written feedback on individual writers. Journal of Second Language Writing, v. 7, n. 3, p. 255-286, 1998.

JOHNSON, D. M. Compliments and politeness in peer-review texts. Applied Linguistics, v. 13, n. 1, p. 51-71, 1992.

KEH, C. L. Feedback in the writing process: a model and methods for implementation. ELT Journal, v. 44, n. 4, p. 294-304, 1990.

LEE, I. L2 writing teacher's perspectives, practices and problems regarding error feedback. Assessing Writing, v. 8, p. 216-237, 2003.

LEKI, I. The preferences of ESL students for error correction in college-level writing classes. Foreign Language Annals, v. 24, p. 203-211, 1991.

LONG, M. H. Input and second language acquisition theory. In: GASS, S. M.; MADDEN, C. G. (Ed.). Input in second language acquisition. Rowley, Mass.: Newbury House, 1985. p. 377-393.

LUCENA, A. M. C. Revisão colaborativa de textos no $2^{\circ}$ grau. Trabathos em Lingüistica Aplicada, Campinas, v. 29, p. 5-19, 1997. 
MURPHY, S. A sociocultural perspective on teacher response: is there a student in the room? Assessing Writing, v. 7, p. 79-90, 2000.

SWAIN, M. The output hypothesis and beyond: mediating acquisition through collaborative dialogue. In: LANTOLF, J. P. (Ed.). Sociocultural theory and second language learning. Hong Kong: Oxford University Press, 2000. p. 97-114.

TSUI, A. B. M. Learning how to teach ESL writing. In: FREEMAN, D.; RICHARDS, J. C. (Ed.). Teacher learning in language teaching. New York: Cambridge University Press, 1996. p. 97-119.

VILLAMIL, O. S.; GUERRERO, M. C. M. de. Peer revision in the 12 classroom: social-cognitive activities, mediating strategies, and aspects of social behavior. Journal of Second Language Writing, v. 5, n. 1, p. 51-75, 1996.

VYGOTSKY, L. S. A formação social da mente: o desenvolvimento dos processos psicológicos superiores. São Paulo: Martins Fontes, 1998.

WALKER, C. Teacher dominance in the writing conference. Journal of Teaching Writing, v. 11, n. 1, p. 65-87, 1992.

ZAMEL, V. Responding to student writing. Tesol Quarterly, v. 19, n. 1, p. 79-97, 1985.

Recebido em: 8 jan. 2005

Aceito em: 10 maio 2005 